\title{
Research Paper: The Effect of Family-Centered Nature Therapy on Interactions Between Parent and Child With Autism Spectrum Disorder
}

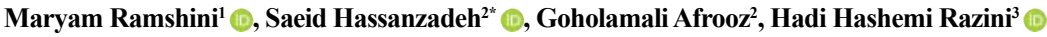 \\ 1. Department of Psychology, Faculty of Literature Humanities and Social Sciences, Science and Research Branch, Islamic Azad University, Tehran, Iran. \\ 2. Department of Psychology, Faculty of Psychology and Education, University of Tehran, Tehran, Iran. \\ 3. Department of Psychology, Faculty of Psychology and Education, Kharazmi University, Tehran, Iran.
}

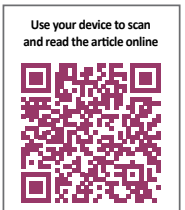

Citation Ramshini M, Hassanzadeh S, Afrooz Gh, Hashemi Razini H. The Effect of Family-Centered Nature Therapy on Interactions Between Parent and Child With Autism Spectrum Disorder. Iranian Rehabilitation Journal. 2018; 16(4):379-386. http://dx.doi.org/10.32598/irj.16.4.379

http://dx.doi.org/10.32598/irj.16.4.379

Article info:

Received: 26 Apr 2018

Accepted: 15 Aug 2018

Available Online: 01 Dec 2018

Keywords:

Autism, Family-centered, Eco therapy

\section{ABSTRACT}

Objectives: Parents of Autism Spectrum Disorder (ASD) children often have a negative attitude towards themselves. They are often negatively affected by these challenges and the failure of their children. Thus, their interaction with their children is negatively influenced. The present study aimed to investigate the potential effect of family-centered nature therapy on the interaction of parents with their children.

Methods: The present research was a quasi-experimental study with pre-test and post-test design and a control group. Statistical population included all ASD children aged 3-7 years in Tehran City, Iran. A sample of 14 children with ASD were selected through convenience sampling method. The subjects were non-randomly assigned into either the experimental or control groups. The necessary data were collected through Parent-Child Relationship Scale (PCRS) and the program of nature therapy developed on the basis of the current theoretical frameworks and research findings. The collected data were subjected to descriptive statistical analyses and Analysis of Covariance (ANCOVA).

Results: The obtained results suggested that the Mean \pm SD score of experimental group on PCRS after the treatment was $100.14 \pm 11.82$. While the Mean \pm SD score of the control group was $84.14 \pm 3.93$. Moreover, the results of the statistical tests revealed that the difference between the experimental and control groups was statistically significant, indicating that the family-centered nature therapy was effective in improving the parents' interactions with their ASD children. In addition, the ANCOVA results indicated that the estimated $\mathrm{F}$ (13.32) was statistically significant at $\mathrm{P}=0.001$, indicating that the treatment had a positive effect on the dependent variable.

Discussion: Family-centered nature therapy was effective in improving the parents' relationship with their children. The ASD children had fewer conflicts with their parents, enjoyed a positive relationship with their parents, and showed lower dependence on their parents after receiving the treatment. Therefore, this therapy can be a complementary method along with other standard treatments received by ASD children. It is an effective, simple and readily accessible option to improve the interaction of parents with their ASD children.

\section{* Corresponding Author:}




\section{Highlights}

- Family-centered nature therapy is effective on children with autism.

- Nature therapy improves parent-child relationship for autism children.

- Nature therapy increases autism children's interactions.

\section{Plain Language Summary}

Study population comprised all autism children aged 3-7 years living in Tehran City, Iran. According to the study results, the difference between the experimental and the control groups was statistically significant, indicating that the family-centered nature therapy was effective in improving the parents' interactions with their autistic children.

\section{Introduction}

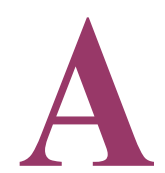

ccording to the Fifth Edition of Diagnostic and Statistical Manual for Mental Disorders, the diagnostic criteria for Autism Spectrum Disorder (ASD) include persistent deficit in social interactions in various contexts, along with the current or past restricted repetitive patterns of interests, behavior and activities observed in the early stages of development, which cause clinically important problems in one's current functioning. The symptoms widely vary based on the severity of ASD, developmental stage, and biological age of the patient [1].

The primary cause of this disorder remains unclear. However, genetic factors play a comparatively important role in autism occurrence. ASD occurrence is critically rising, as 1 in each 68 children is diagnosed with ASD [2]. The frequency and type of interactions in ASD children with their parents, negatively affect the relationship between them [3]. Parents often report high degrees of anxiety, depression, isolation, separation and aggression in their ASD children. These behavioral problems lead to personal distress in parents. The gradually exacerbating temper of parents of ASD children, negatively impacts parent-child interactions.

Investigating parent-child relationship in families with an ASD member started in 1980s. The relevant results revealed that the parents of ASD children were under stress and faced with a variety of life challenges. Issues such as socio-behavioral problems, bad-temperedness, self-injury, other injury, and verbal problems that cause changes in the interaction between ASD children with their parents and even with other family members $[4,5]$. Such problems complicate child raising for the parents, thus negatively influence the parent-child interactions $[6,7]$.

The developmental characteristics of child and parents' characteristics are important and form the nature of parent-child relationship. In the theory of systemic family therapy, all family members are believed to be involved in the parent-child relationship [8]. Thus, using parents as therapists in the treatment of ASD children seems to be a logical effective strategy. Such strategy provides the parents with a chance to be more active in taking care of their children and have a better understanding of their children's desires and real needs.

A variety of treatment methods have been implemented by experts to improve the quality of the development of ASD children through eliminating the problems. The use of special treatment for ASD children initiated in 1960. Psychoeducational, medical, complementary or alternative treatments are currently available. However, nature therapy has been introduced since 1992, as a type of ecopsychology approach [9].

Nature therapy refers to all treatments in which a variety of activities are performed in nature, outdoors, and green areas [10]. This treatment approach is followed in an experimentally creative manner in the nature. Nature therapy extends our classic understanding of place as a static concept into a dynamic one under the control of the therapist. Such place is used to form the structure, conditions, and process of treatment [11]. In nature therapy, a number of interventions are made by the therapist, including animal assisted intervention, horticultural therapy, farming, performing art in or with nature, wilderness therapy, adventure therapy, and green exercise therapy [12]. 
Much research indicate that experiencing and interacting with nature have positive effects on cognitive, physical, social and emotional development of children. However, the lack of relation with nature is associated with adverse effects on the development and health of children. For example, studies in the field of education revealed that nature has positive effects on the cognitive, emotional, and social development in children with attention deficit disorder, as well as attention deficit hyperactivity disorder [13].

Similarly, a study conducted by the Psychotherapy Center [14] reported that exposing hospital patients to beautiful natural sites have some positive benefits for them like reduced stress, increased self-esteem, weight loss, and reduced substance abuse. Moreover, Culture and Wilkins (1992) applied nature therapy to cure ASD children, abnormal growth, conduct disorder, disregard disorder, severe emotional disorders, and learning disorders. Their obtained results included a reduction in aggressive and hostile behavior, developing cooperative behavior with peers, as well as increase in social skills and self-confidence $[15,16]$. Moreover, being attracted by the nature can be considered as a type of self-therapy. Nature therapy increases sensory stimulation, attention, care, a sense of security, happiness and well-being. It also decreases stress level, and mental fatigue.

The integration of nature therapy and family-centered approach could be applied in the treatment of children with ASD. Such integration provides a chance to experience nature, and enables parents to improve the quality of their interaction with their ASD children in the calmness of nature [17]. Thus, the present study aimed to investigate the potential positive effect of familycentered nature therapy on the parent interactions with their children with ASD.

\section{Methods}

This quasi-experimental study was of pretest-posttest control group design. The statistical population included all ADS children aged 3-7 years referred to rehabilitation centers and clinics in Tehran City, Iran. A sample of 14 ASD children were selected from 3 health centers (Health Center of Seda-o-Sima, Zafar, Padideh). Samples were non-randomly assigned to either the experimental or the control groups, by convenience sampling method. After the children were diagnosed with autism by a psychiatrist in the relevant centers, the parents were briefed on the purpose and conditions of the study. They were explained that the presence of both parents or one parent in all treatment sessions was necessary. Finally, the parents of 14 ASD children (12 males and 2 females) without any mental disorders, attention deficit disorder, and hyperactivity disorder agreed to participate in the study. There were 6 males and 1 female in each group.

The exclusion criteria were any mental disorder identified as the primary diagnosis, absence from 2 or more sessions, and any physical illness. The study participants had received psychological therapies at the clinics before and during the course of the present study. The participants attended ten 3-hour long treatment sessions in 3 months at Savan Nature School in Tehran. The introductory session for the parents of the experimental group was held at TV Health Center building in June 2017 in the presence of the specialist and all staff of the center. The written informed consent was obtained from all parents of the subjects after being informed about the purpose of the study and confidentiality of their information. Then, 10 treatment sessions were held in the nature. In each session, some predetermined tasks and activities as introduced in Table 1 were performed.

Before conducting the study, the parents of both groups were required to complete the Child-Parent Relationship Scale (CPRS) (Pianta, 1994) as the pretest. Because in every session, the parents and children were present in the nature, the researcher requested the staff of the center to cooperate with the parents as facilitators, to provide more safety for the parents and children. At the beginning of every treatment session, the researcher explained the relevant tasks and activities in details for the parents and facilitators. The parents were required to cooperate with the facilitator and their children to complete the assigned activities.

In some activities, the parents had to work alone with their children to complete the assigned activities. Ten days after the last treatment session, the CPRS was completed by the parents of both groups as the posttest. The same scale was again completed by the parents after 3 months as the follow-up test. The present study was confirmed by the Ethics Committee of Islamic Azad University, Science and Research Branch, Tehran and the Health Center of Seda-o-Sima in Tehran.

\section{Study tools}

Child-Parent Relationship Scale (CPRS) developed by Pianta (1994), was translated into Persian by Abareshi, Tahmasian, Mazaheri, and Panahi (2007). The validity and reliability of the translated version of the scale was confirmed by specialists. This scale is among the most powerful measures of parent-child relationship, and es- 
Table 1. Tasks assigned in the treatment sessions

\begin{tabular}{|c|c|}
\hline Session & Completed Tasks \\
\hline First & $\begin{array}{c}\text { Being in the nature (getting interested and mentally involved in the nature without the direct guidance of the trainer) } \\
\text { Performing a variety of tasks, including sitting on lawn, lying on lawn }\end{array}$ \\
\hline Second & $\begin{array}{l}\text { Repeating previous session tasks and performing special activities with a focus on visual, tactile, and vestibular } \\
\text { stimulation. Walking along an imaginary path and collecting stones along the road and putting them into a bag, } \\
\text { covering the body with soil and mud, performing balance activities }\end{array}$ \\
\hline Third & $\begin{array}{c}\text { Repeating previous session tasks and performing activities focused on auditory, taste, tactile, and olfactory stimulation } \\
\text { Collecting wood to start a fire, roasting potatoes on fire, peeling and eating potatoes, smelling the bread heated } \\
\text { on fire, walking on dried tree leaves }\end{array}$ \\
\hline Fourth & $\begin{array}{l}\text { Repeating previous session tasks and performing activities focused on vestibular stimulation. } \\
\text { Keeping the body in different positions in the air, touching animals, hugging animals, making mud and putting } \\
\text { mud on hand, trunk and the leg }\end{array}$ \\
\hline Fifth & $\begin{array}{l}\text { Repeating previous session tasks and performing activities focused on sight and tactile stimulation. } \\
\text { Playing Haft Sang (Persian game), playing bowling using wood pieces, hiding the body under the sand and gravels }\end{array}$ \\
\hline Sixth & $\begin{array}{l}\text { Repeating previous session tasks and performing activities focused on vestibular stimulation. } \\
\text { Touching dried tree leaves with the body, performing activities like jumping, running, etc. Collecting small and big } \\
\text { stones, picking up dried leaves from the lawn, feeding animals, cooking Mirzaghasemi (a Persian dish) with the } \\
\text { help of parents }\end{array}$ \\
\hline Seventh & $\begin{array}{l}\text { Repeating previous session tasks and performing activities focused on auditory, sight, and tactile stimulation. } \\
\text { Leaning against a tree and scratching the back with the tree, sitting by a stream and listening to the sound of run- } \\
\text { ning water }\end{array}$ \\
\hline Eighth & $\begin{array}{l}\text { Repeating previous session tasks and performing activities focused on olfactory, vestibular, and sight stimulation. } \\
\text { Collecting vegetables, smelling vegetables, climbing a spider web while maintaining balance }\end{array}$ \\
\hline Ninth & $\begin{array}{l}\text { Repeating previous session tasks and performing activities focused on sight and olfactory stimulation. } \\
\text { Walking on the edge of stones around raised garden beds, watering tomato plants using a glass }\end{array}$ \\
\hline Tenth & $\begin{array}{l}\text { Repeating previous session tasks and performing activities focused on taste, tactile, and olfactory stimulation. } \\
\text { Going into the birds and rabbits cage, hugging them, and feeding them, smelling burned wood, making bread } \\
\text { (mixing flour with water) }\end{array}$ \\
\hline
\end{tabular}

pecially mother-child relationship. It consists of 30 items organized in 3 different subparts of conflict (items 6, 28, $27,26,25,24,23,21,19,17,14,12,7,4,2)$, positive relationship (items $8,5,3,1,30,29,22,16,13,10$ ), and dependence (items 20, 18, 15, 11,9), with the Cronbach alpha of $0.84,0.69,0.46$, respectively. This scale measures parents' understanding of their relationship with their children. This scale can be self-administered to measure parent-child relationship, based on a 5-point Likert-type scale, with 1 indicating "definitely apply" and 5 indicating "definitely does not apply" $[18,19]$.

Family-centered Nature Therapy Program consists of 2 different stages; 1. Making children interested and mentally involved in nature; 2 . being present in nature and performing certain predetermined activities and tasks. The first stage contains free activities which are not under the direct control of researcher. However, the second stage consists of 3 parts, as follows: completing horticultural therapy activities, establishing relationship with animals in the natural environment, and performing physical activities in the nature. In each part, certain activities are performed.

The physical activities consisted of 6 groups of activities, each focuses on 1 of the 5 senses of sight, hearing, olfactory, taste, and the vestibular sense. The activities performed in each stage are confirmed by 5 different specialists. All of the aforementioned activities and tasks were based on the documentation mentioned in other research studies. The validity of the program was confirmed by relevant professors and specialists and occupational therapists, and their content was content.

\section{Results}

The collected data were analyzed by descriptive inferential statistics including Analysis of Covariance (ANCOVA). Tables 2 and 3 summarize the measures of central tendency and dispersion for the PCRS obtained 
scores. Those tables also present the follow-up test results for the experimental and control groups.

As per Table 2, the Mean \pm SD scores for the 3 subparts of the scale are presented separately. The scores of the experimental group on the PCRS yielded Mean \pm SD score of $83.14 \pm 8.13$. However, after the treatment, the experimental group obtained Mean \pm SD score of $100.14 \pm 11.82$ on PCRS. The control group demonstrated Mean \pm SD score of $88.71 \pm 7.83$ on the scale before conducting the study. In addition, the Mean \pm SD score of PCRS was $87.14 \pm 3.93$, after the treatment. Also, the Mean \pm SD score of the follow-up test for the experimental group revealed a negligible difference with those obtained in the post-test. Before running the parametric ANCOVA, the normality of dispersion and the assumption of homogeneity of variance were confirmed through KolmogorovSmirnov Test and the Levene's Test.

According to Table 3, the obtained F-value of 13.32, was statistically significant at $\mathrm{P}=0.001$. Given the fact that the significance level selected for the present study was $\mathrm{P}=0.05$, the obtained F-value was definitely significant. Such finding indicates that the treatment provided (independent variable) for the experimental group was effective in modifying parent-child interaction (dependent variable). Thus, the obtained results suggested that family-centered nature therapy improved the parent-child interaction in the experimental group. In other words, the provided treatment (independent variable) explained

Table 2. The Mean \pm SD of the pre-test and post-test scores of the experimental and control groups based on PCRS and follow-up data

\begin{tabular}{|c|c|c|c|c|c|c|}
\hline Subparts & Group & Test & No. & Mean士SD & Min & Max \\
\hline & & Pre-test & 7 & $30.57 \pm 9.3$ & 31 & 52 \\
\hline \multirow[t]{2}{*}{ Conflict } & Experimental & & & & & \\
\hline & & Post-test & 7 & $41.29 \pm 7.25$ & 16 & 40 \\
\hline \multirow[t]{4}{*}{ Follow-up } & & & & $40.41 \pm 6.59$ & & \\
\hline & & Pre-test & 7 & $25.71 \pm 6.63$ & 15.00 & 37.00 \\
\hline & Control & & & & & \\
\hline & & Post-test & 7 & $22.00 \pm 5.39$ & 14.00 & 29.00 \\
\hline \multirow{3}{*}{ Positive relationship } & & Pre-test & 7 & $24.86 \pm 6.23$ & 16.00 & 32.00 \\
\hline & Experimental & & & & & \\
\hline & & Post-test & 7 & $33.300 \pm 5.13$ & 25.00 & 39.00 \\
\hline \multirow[t]{3}{*}{ Follow-up } & & & & $34.00 \pm 5.65$ & & \\
\hline & & Pre-test & 7 & $22.00 \pm 2.77$ & 18.00 & 26.00 \\
\hline & & Post-test & 7 & $2171+411$ & 1400 & 2600 \\
\hline \multirow{3}{*}{ Dependence } & & Pre-test & 7 & $10.29 \pm 3.40$ & 5.00 & 16.00 \\
\hline & Experimental & & & & & \\
\hline & & Post-test & 7 & $13.00 \pm 2.24$ & 9.00 & 15.00 \\
\hline \multirow[t]{4}{*}{ Follow-up } & & & & $12.00 \pm 2.51$ & & \\
\hline & & Pre-test & 7 & $7.14 \pm 2.54$ & 4.00 & 12.00 \\
\hline & Control & & & & & \\
\hline & & Post-test & 7 & $6.29 \pm 2.87$ & 4.00 & 12.00 \\
\hline \multirow{3}{*}{ Parent-child relation } & & Pre-test & 7 & $83.14 \pm 8.13$ & 70.00 & 94.00 \\
\hline & Experimental & & & & & \\
\hline & & Post-test & 7 & $100.14 \pm 11.82$ & 82.00 & 116.00 \\
\hline \multirow[t]{3}{*}{ Follow-up } & & & & $97.00 \pm 11.59$ & & \\
\hline & & Pre-test & 7 & $88.71 \pm 7.83$ & 77.00 & 99.00 \\
\hline & है⿴囗十⺝木 & Pest-tect & 7 & $7814+393$ & 810 & ח0 \\
\hline
\end{tabular}


Table 3. The results of the ANCOVA (the effect of nature therapy program on parent-child relationship)

\begin{tabular}{ccccccc}
\hline Source of Variance & SSE & df & MSE & F & Significance Level & Eta-Squared \\
\hline Experiment & 430.61 & 1 & 430.61 & 13.32 & & 0.55 \\
Error & 355.51 & 11 & 32.32 & & \\
Total & 872.93 & 13 & & & 0.001 \\
\hline
\end{tabular}

Iranian Rehabilitation Journa!

$55 \%$ of the observed variance of the scores related to the dependent variable.

\section{Discussion}

The present study mainly aimed to investigate the potential effect of family-centered nature therapy on parentchild interaction patterns among families with ASD children. The results revealed that the posttest mean score of experimental group was significantly higher than that of the control group. These data suggest that the treatment provided to the experimental group was effective in modifying the interactions between parents and their ASD children. In other words, the family-centered nature therapy significantly improved the parent-child interaction pattern. However, the improvement in parent-child interaction takes place when there is a mutual emotional expression and interaction between them.

There are a number of factors which facilitate the mutual emotional child-parent interactions. Perhaps the most important factor is their well-being. Firstly, the children feel well when the parents are actively present and involved in training them. in that the parents' presence fosters close emotional relationships between the parents and the kid, thus helping the child to feel safe and secure $[20,21]$. Secondly, as the results of the present study indicate, the presence of parents and children in the nature improves the social, communicative and other skills in the children.

The ASD children's parents are under extreme amount of stress due to the specific challenges and problems associated with ASD children, including social, and unpredictable behavioral problems. However, when they are actively engaged in the treatment process, they can have more interaction with the specialists. Thus, they can be better informed about the real needs, desires, strengths and weaknesses of their child. The ASD children's parents are supposed to have constant relationship with their children throughout their lives. Therefore, it is important for them to be actively engaged in the process of training their children and supporting them. In this way, they feel in control of the situation, have more self-confidence in establishing and adjusting their interactions with their ASD children. As a result, they feel less stressed due to feeling more intimate emotional bond with their children, and an improved interaction with their children [22]. Moreover, when children with ASD perform different activities in the nature in the presence of their parents (e.g. climbing a tree), they ask for their parents help. Thus they have a chance to improve their relationship with their parents [23].

Studies focusing specifically on the effect of familycentered nature therapy on the parent-child interaction are scarce. The majority of studies available have focused on the participation of parents in other training programs, with few studies investigating the nature therapy. However, the results obtained in the present study are in line with those by Selinger and Elder [24], Par, Grey, Wigham et al. [25], Fiona, Lacroix and Luis [26], and Lunsky and Weiss [27].

In their study on ASD children, Selinger and Elder [24] reported that the participation of parents in training interventions decreased the undesirable behavior in ASD children, thus improved the parent-child interaction. The study by Par et al. [25] revealed that a family-centered approach for the treatment of ASD children had a positive effect on the parent-child interaction and improved the self-confidence in parents.

Fiona, Lacroix and Luis found that playing with sand considerably improved interactions between ASD children and their parents and others [26]. Lunsky and Weiss investigated parent-child interaction among children with ASD and reported a high level of stress in the mothers of ASD children due to the challenging behavior of their children [27]. They reported a positive correlation between the psychological problems of ASD children and the stress level their parents undergo. This issue has direct negative influence on the interaction of these parents with their autistic children. 


\section{Conclusion}

The results suggest that the provision of family-centered nature therapy for ASD children results in a considerable improvement in the parent-child interaction. There are however some limitations to the present study. Because the presence of parents were necessary, the number of treatment sessions was limited, and the parents could not attend more sessions due to their employment conditions.

It is suggested that the family-centered nature therapy be used as a complementary treatment along with other treatment strategies for children with ASD of all ages, and even for children with other special needs, to improve the growth of these children, and improve the mental health of their families.

\section{Ethical Considerations}

\section{Compliance with ethical guidelines}

This study was approved by the Ethics Committee of Islamic Azad University of Science and Research Branch.

\section{Funding}

This research did not receive any specific grant from funding agencies in the public, commercial, or not-forprofit sectors.

\section{Authors contributions}

All authors had contribution in writing this paper, and for it was prepared and analyzed according to the opinion of all authors.

\section{Conflict of interest}

The authors declared no conflict of interest.

\section{Acknowledgements}

I would like to express my special gratitude to Dr. Hosseini (the head of the Health Center of Seda-o-Sima), Dr. Karimi (the specialist at Health Center) and the parents of children participating in this study, for their kind cooperation with the researcher.

\section{References}

[1] American Psychological Association. Diagnostic and statistical manual of mental disorders [F Rezaee, A Fakhraei, A Farmand, Persian Trans.]. Tahran: Arjmand; 2013.

[2] Sealey LA, Hughes, BW, Sriskanda AN, Guest JR, Gibson AD, Johnson L, et al. Environmental factors in the developmental of autism spectrum disorders. Environmental International. 2016 88:288-98. [DOI:10.1016/j.envint.2015.12.021] [PMID]

[3] Russell S, McCloskey CR. Parent perceptions of care received by children with an autism spectrum disorder. Journal of Pediatric Nursing. 2016; 31(1):21-31. [DOI:10.1016/j. pedn.2015.11.002] [PMID]

[4] Donnelly LJ. Parent-child interaction in children with autism spectrum disorder who vary in symptom severity and level of functioning. New York: Academic Commons; 2015. [DOI:10.7916/D8028QZ0]

[5] Howell Erica LLS, Blacher J. Family impact of children with autism and asperger syndrome: A case for attention and intervention. Austin Journal of Autism \& Related Disabilities. 2015; $1(2): 2-9$

[6] Eskandari B, Pouretemad H, Habibi Asgarabad M, Mazaheri Tehrani MA. [Effect of sensory processing style interventions on increasing parental self-efficacy and child-parent relationship in children with autism (Persian)]. Exceptional Education. 2016; 1(138):14-21.

[7] Kayfar MS, Yazdi SAA, Karashki H. [The effect of familybased therapy on the interaction of the mother-child and the prevalence of aggression in preschool children (Persian)]. Research in Clinical Psychology and Consultation. 2013; 4(2):18-4

[8] Mohtashemi T, Ebrahimi F, Aliakbari Dehkordi M, Chimeh N. [Comparison of parental stress, satisfaction, family function of mothers of children with autism with mothers of normal growths (Persian)]. Journal of Exceptional Children. 2016; 4:51-62.

[9] Louv R. Last child in the woods: Saving our childran from nature-deficit disorder. New York: Algonquin Books; 2008.

[10] Revell S, Duncan E, Cooper M. Helpful aspects of outdoor therapy experiences: An online preliminary investigation Counselling and Psychotherapy Research. 2014; 14(4):281-7. [DOI:10.1080/14733145.2013.818159]

[11] Berger R. Beyond words: Nature-therapy in action. Journal of Critical Psychology, Counseling And Psychotherapy. 2006; 6(4):1-6.

[12] Sempik J. Green care and mental health: Gardening and farming as health and social care. Mental Health and Social Inclusion. 2010; 14(3):15-22.

[13] Mustapa ND, Maliki NZ, Hamzah A. Repositioning children's developmental needs in space planning: A review of connection to nature. Procedia-Social and Behavioral Sciences. 2015; 170:330-9. [DOI:10.1016/j.sbspro.2015.01.043]

[14] Apathy M. An exploration of the ways psychotherapists think about the human-nature relationship and the clinical implications of this in Aotearoa-New Zealand [MSc. thesis]. Auckland: Auckland University of Technology; 2014.

[15] Kahn PH, Kellert SR. Children and nature: Psychological sociocultural and evolutionry investigations [AH Vahabzade, 
A Hosseinian, Persian trans.]. Mashhad: Jahad Daneshgahi Mashhad; 2002.

[16] Adams M, Jordan M, Wren J, Wright J. The grow project: A report on the Well-being benefits of nature connection for peple with experience of mental distress. Brighton:University of Brighton; 2014.

[17] Brown D, Barton JL, Pretty J, Gladwell VF. Assessing the role of the natural environment in a work place physical activity intervention. Scandinavian Journal of Work, Environment \& Health. 2014; 40(4):390-9. [DOI:10.5271/sjweh.3421] [PMID]

[18] Abareshi Z, Tahmasian K, Mazaheri MA, Panahi L. [The effect of education on child psychosocial promotion through improving mother-child interaction on parental self-efficacy and the relationship between mother and child under the age of three (Persian)]. Journal of Research in Psychological Health. 2009; 3(3):49-57.

[19] Pianta RC. Patterns of relationships between children and kindergarden. Journal of School Psychology. 1994; 32(1):1532. [DOI:10.1016/0022-4405(94)90026-4]

[20] McDonald NM, Baker JK, Messinger DS. Oxytocin and parent-child interaction in the development of empathy among children at risk for autism. Developmental Psychology. 2016; 52(5):735-45. [DOI:10.1037/dev0000104] [PMID] [PMCID]

[21] Corazon SS, Stigsdotter UK, Jensen AG, Nilsson K. Development of the nature-based therapy concept for patients with stress-related illness at the Danish healing forest garden Nacadia. Journal of Therapeutic Horticulture. 2010; 20:33-51.

[22] Shire SY, Goods K, Shih W, Distefano C, Kaiser A, Wright $\mathrm{C}$, et al. Parents' adoption of social communication intervention strategies: Families including children with autism spectrum disorder who are minimally verbal. Journal of Autism and Developmental Disorders. 2015; 45(6):1712-24. [DOI:10.1007/s10803-014-2329-x] [PMID] [PMCID]

[23] Rat W. Science-Study and teaching (Early childhood)Activity program [AH Vahabzade, Persian trans.]. Mashhad: Sahra; 2016.

[24] Sellinger VJ, Elder JH. Parent training intervention to manage externalizing behaviors in children with autism. Journal of Pediatric Health Care. 2016; 30(1):73-7. [DOI:10.1016/j. pedhc.2015.10.002] [PMID]

[25] Parr JR, Gray L, Wigham S, McConachie H, Le Couteur A. Measuring the relationship between the parental broader autism phenotype, parent-child interaction, and children's progress following parent mediated intervention. Research in Autism Spectrum Disorders. 2015; 20:24-30. [DOI:10.1016/j. rasd.2015.07.006]

[26] Lu L, Petersen F, Lacroix L, Rousseau C. Stimulating creative play in children with autism through sandplay. The Arts in Psychotherapy. 2010; 37(1):56-64. [DOI:10.1016/j. aip.2009.09.003]

[27] Weiss JA, Lunsky Y. The brief family distress scale: A measure of crisis in caregivers of individuals with autism spectrum disorders. Journal of Child and Family Studies. 2011; 20(4):521-8. [DOI:10.1007/s10826-010-9419-y] 